\title{
DISSOCIATIVE IONIZATION BY LOW ENERGY ELECTRON IMPACT. ENERGY DISTRIBUTION AND APPEARANCE ENERGY OF DOUBLY IONIZED FRAGMENTS FROM $\mathrm{N}_{2}$ AND $\mathrm{O}_{2}$
}

\author{
R. LOCHT and J. МOMГGNY \\ Département de Chimie Générale et de Chimie-Physique, Institut de Chimie, Université de Liège, B-4000 Liège \\ I, Belgium
}

Ion energy distributions and threshold energies are measured for the appearance of $\mathrm{N}^{2+}$ from $\mathrm{N}_{2}$. To our knowledge the same data are measured for the first time on $\mathrm{O}^{2+}$ from $\mathrm{O}_{2}$. For both ions a thermal peak is observed in the ion energy distribution having an onset at $(61.1 \pm 0.5) \mathrm{eV}$ and $(60.5 \pm 0.8) \mathrm{eV}$ for the $\mathrm{N}^{2+}$ ion and the $\mathrm{O}^{2+}$ ion respectively. The appearance energy of higher energetic ions is measured and interpreted.

Since the paper of Hagstrum [1] in 1941 only a few studies were concerned with the formation of doubly ionized species. After a large time gap of about two decades, Kieffer and van Brunt [2] observed $\mathrm{N}^{2+}$ ions formed by electron impact on $\mathrm{N}_{2}$. The appearance energy as well as the kinetic energy distribution of this ion have been measured. Crowe and McConkey [3] and Deleanu et al. [4] revised the $\mathrm{N}^{2+}$ ion formation by electron impact on $\mathrm{N}_{2}$ and measured the angular dependence of the ion energy distribution. However a large discrepancy exists between the appearance energy for $\mathrm{N}^{2+}$ measured by these authors. Furthermore, though the authors have purposely searched for [3], no thermal ions have been observed in the $\mathrm{N}^{2+}$ ion energy distribution. Recently Edwards et al. [5] measured $\mathrm{N}^{2+}$ ion energy distributions formed by $1 \mathrm{MeV} \mathrm{H}^{+}$and $\mathrm{He}^{+}$ion impact on $\mathrm{N}_{2}$. Hurley [6] made theoretical predictions of potential energy curves for doubly positive diatomic ions such as $\mathrm{N}_{2}{ }^{2+}, \mathrm{O}_{2}{ }^{2+}$ and $\mathrm{NO}^{2+}$.

To our knowledge, no data obtained in comparable experimental conditions have been published about $\mathrm{O}^{2+}$ formation from $\mathrm{O}_{2}$. We investigated $\mathrm{N}^{2+}$ from $\mathrm{N}_{2}$ and $\mathrm{O}^{2+}$ from $\mathrm{O}_{2}$ for three reasons: (i) to try to elucidate the existing discrepancy between the measured appearance energies, (ii) to find out whether $\mathrm{N}^{2+}$ thermal ions are formed or not and finally (iii) to measure the same data for $\mathrm{O}^{2+}$ from molecular oxygen.

The instrument used as well as the experimental conditions have extensively been described elsewhere $[7,8]$. To avoid a too quick burn-out of the filament due to the presence of oxygen, all the data reported here were obtained with an electron beam intensity of $1 \mu \mathrm{A}$ and at a total pressure of $2 \times 10^{-7}-4 \times 10^{-7}$ Torr of air dried in a liquid nitrogen trap. Previous experiments [3,4] were performed at pressures of two orders of magnitude higher. Because of the low intensity of the $\mathrm{N}^{2+}$ and $\mathrm{O}^{2+}$ signals, (i) the ion accelerating voltage has been set at $4 \mathrm{~V}$ or $5 \mathrm{~V}$ at the expense of the kinetic energy resolution and (ii) the signals stored in a multichannel analyser have been averaged during $48-80 \mathrm{~h}$ and all critical energies are obtained from at least 5 independent measurements.

For the $\mathrm{N}^{2+}$ ions formed by dissociative ionization of $N_{2}$, fig. 1 shows the ion energy distribution as observed for different electron energies ranging from $60-100 \mathrm{eV}$. Peak maxima are measured at thermal energy with low intensity at high electron energy, at $(1.2 \pm 0.1) \mathrm{eV},(3.0 \pm 0.1) \mathrm{eV},(4.1 \pm 0.1) \mathrm{eV}$ and around $7 \mathrm{eV}$. The peak observed at $4.1 \mathrm{eV}$ for $75 \mathrm{eV}$ and $80 \mathrm{eV}$ electron energy shifts to $4.8 \mathrm{eV}$ at $100 \mathrm{eV}$ electron energy. Crowe et al. [3] mention peak maxima at $2.9 \mathrm{eV}, 5.1 \mathrm{eV}$ and $7.9 \mathrm{eV}$. Edwards et al. [5] using a $1 \mathrm{MeV} \mathrm{H}^{+}$ion beam found structures at $(2.3 \pm 0.5) \mathrm{eV},(5.3 \pm 0.3) \mathrm{eV}$ and $(10.2 \pm 0.5) \mathrm{eV}$ in the $\mathrm{N}^{2+}$ ion energy distribution. With a $\mathrm{He}^{+}$beam [5] the distribution is modified and peak maxima were measured at $(4.2 \pm 0.5) \mathrm{eV},(6.6 \pm 0.3) \mathrm{eV}$, $(12.1 \pm 0.5) \mathrm{eV}$ and at $(16.0 \pm 0.6) \mathrm{eV}$.

In the present experiment the existence of thermal $\mathrm{N}^{2+}$ ions is confirmed at all electron energies and their relative intensity increases from $100 \mathrm{eV}$ to an energy close to threshold (see fig. 1). The peak at $1.2 \mathrm{eV}$, only slightly visible as a shoulder at high electron energies in the $3.0 \mathrm{eV}$ peak, is well resolved and isolated at 65 $\mathrm{eV}$ electron energy. The second important feature is that the $\mathrm{N}^{2+}$ signal is not observed at $60 \mathrm{eV}$ electron energy. 
Fig. 1. $\mathrm{N}^{2+} / \mathrm{N} 2$ ion energy distributions observed for 100, 75, 70, 65, and $60 \mathrm{eV}$ electron energy.

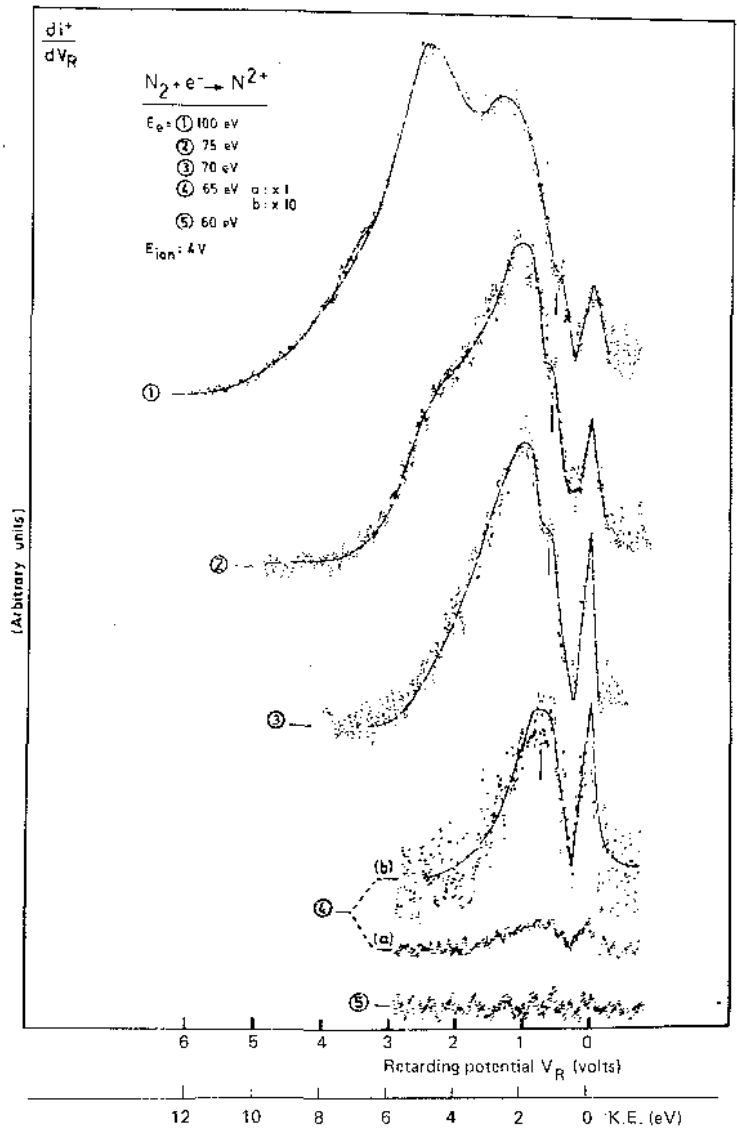

The baseline reproduced in fig. 1 and recorded for $60 \mathrm{eV}$ electron energy, as well as the signal at $65 \mathrm{eV}$ are obtained after $80 \mathrm{~h}$ of accumulation in the multichannel analyser. No doubt remains about the position of the appearance potential of $\mathrm{N}^{2+}$ from $\mathrm{N}_{2}$ between 60 and $65 \mathrm{eV}$, in drastic disagreement with Deleanu et al. [4] who measured the threshold at $(54 \pm 2) \mathrm{eV}$. However, Kieffer et al. [2] and Crowe et al. [3] measured the appearance energy for the same ion at $61 \mathrm{eV}$ and $(60.3 \pm 2) \mathrm{eV}$ respectively.

We measured the $\mathrm{N}^{2+}$ electron ionization efficiency curve as well as its first derivative as shown in fig. 2. The energy scale is calibrated with the appearance energy of $\mathrm{N}^{+}$from $\mathrm{N}_{2}$ at $24.3 \mathrm{eV}$ [8], The lowest threshold energy, measured by the vanishing current method in the direct curve and the linear extrapolation in the first differentiated curve, is $(61.1 \pm 0.5) \mathrm{eV}$. This energy corresponds fairly well to the onset calculated for the process at $60.985 \mathrm{eV}$, using $\mathrm{D}_{0}^{0}\left(\mathrm{~N}_{2}\right)=9.759 \mathrm{eV}[9], \mathrm{IP}\left(\mathrm{NI},{ }^{4} \mathrm{~S}^{\circ}\right)=14.534 \mathrm{eV}$ [10], IP $\left(\mathrm{NII},{ }^{3} \mathrm{P}\right)=29.601 \mathrm{eV}[10]$ and the excitation energy of $\mathrm{N}^{2+}\left({ }^{4} \mathrm{P} \leftarrow{ }^{2} \mathrm{P}^{\circ}\right)=7.091 \mathrm{eV}[11]$.

$$
\mathrm{N}_{2}+\mathrm{e}^{-} \rightarrow \mathrm{N}\left({ }^{4} \mathrm{~S}^{\circ}\right)+\mathrm{N}^{2+}\left({ }^{4} \mathrm{P}\right)+3 \mathrm{e}^{-}
$$

This appearance energy characterizes the formation of thermal $\mathrm{N}^{2+}$ ions. The ${ }^{4} \mathrm{~S}^{\circ}$ and ${ }^{4} \mathrm{P}$ terms correlate with singlet, triplet, quintet and septet $\sum_{\mathrm{u}, \mathrm{g}}^{+}$and $\Pi_{u, g}$ states. Information about the symmetry of the final $\mathrm{N}_{2}{ }^{2+}$ state involved at $61.1 \mathrm{eV}$ could not be provided by the angular distribution measurements of Crowe [3] for the following reasons: (i) no thermal ions are observed and angular distributions are recorded for $2.9 \mathrm{eV}$ ions at electron energies of at least $80 \mathrm{eV}$ and (ii) the validity of Dunn's selection rules is questionable for an excitation process involving three outgoing electrons [12]. The potential curves of $\mathrm{N}_{2}{ }^{2+}$ calculated by Hurley [6] are below the energy range of $60 \mathrm{eV}$ and concern only doubly ionized molecular states converging to dissociation limits giving rise to $\mathrm{N}^{+}+\mathrm{N}^{+}$.

We recorded the ionization efficiency curves of $\mathrm{N}^{2+}$ for retarding potentials corresponding to each 
Fig. 2. First differentiated (a) and direct (b) ionization efficiency curve of $N^{2+}$ obtained at $V_{R}=0 \quad V$ and ion accelerating voltage $E_{\text {ion }}=5 \mathrm{~V}$.

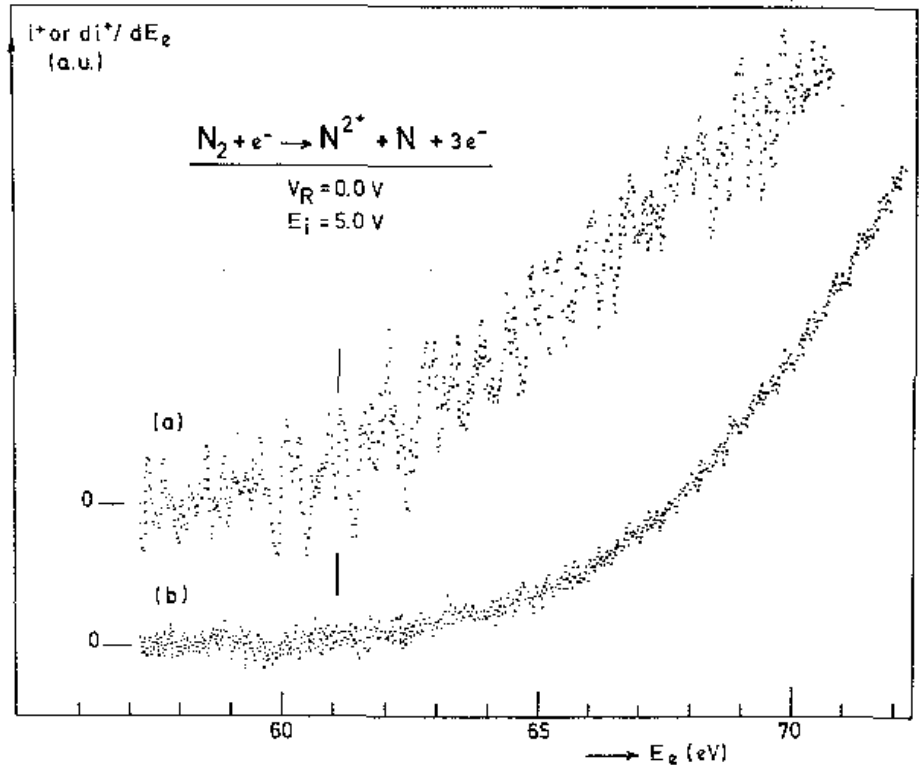

maximum observed in the ion energy distribution. The results are summarized in fig. 3 . The only comparison which could be made with previous results is the appearance energy measured for the $3.8 \mathrm{eV} \mathrm{N}^{2+}$ ions at around $69 \mathrm{eV}$ by Kieffer et al. [2]. This value has to be compared with our value of $(68.7 \pm 0.5) \mathrm{eV}$ for $4 \mathrm{eV} \mathrm{N}^{2+}$ ions.

From these measurements we could deduce that probably three ion groups are formed by the same process (1), i.e. those ions carrying a minimum transjational energy of $0.0,1,2$ and $4.0 \mathrm{eV}$. At $64.7 \mathrm{eV}$, involving $3.0 \mathrm{eV}$ kinetic energy $\mathrm{N}^{2+}$ ions, a lower lying dissociation limit is probably concerned, e.g.

$$
\mathrm{N}_{2}+\mathrm{e}^{-} \rightarrow \mathrm{N}\left({ }^{2} \mathrm{P}^{\circ}\right)+\mathrm{N}^{2+}\left({ }^{2} \mathrm{P}^{\circ}\right)+3 \mathrm{e}^{-}
$$

which is calculated at $56.973 \mathrm{eV}$, using $\mathrm{N}\left({ }^{2} \mathrm{P}^{\circ} \leftarrow{ }^{4} \mathrm{~S}^{\circ}\right)=3.079 \mathrm{eV}[11]$

The high energetic $\mathrm{N}^{2+}$ ions $(7 \mathrm{eV})$ appearing at $78.7 \mathrm{eV}$ could be ascribed to one of the processes

$$
\mathrm{N}_{2}+\mathrm{e}^{-} \rightarrow \mathrm{N}\left({ }^{2} \mathrm{P}^{\circ} / 4\right)+\mathrm{N}^{2+}\left({ }^{4} \mathrm{P} /{ }^{2} \mathrm{P}^{\circ}\right)+3 \mathrm{e}^{-}
$$

which lies in the range of 64.064-64.818 eV. In this energy range four dissociation limits exist where the neutral $\mathrm{N}$ atom is excited in the ${ }^{2} \mathrm{P},{ }^{4} \mathrm{P},{ }^{2} \mathrm{P}$ and ${ }^{4} \mathrm{P}$ levels and the doubly ionized $\mathrm{N}^{2+}$ is in the ${ }^{4} \mathrm{P}$ or ${ }^{2} \mathrm{P}^{\circ}$ level. The uncertainty in our measurements does not allow a more precise assignment in the present case.

For $\mathrm{O}^{2+}$ ions produced by dissociative electron ionization of $\mathrm{O}_{2}$, fig. 4 shows a typical ion energy distribution obtained with $100 \mathrm{eV}$ electrons. Three groups of ions are observed at $(0.0 \pm 0.1) \mathrm{eV},(1.4 \pm 0.2) \mathrm{eV}$ and $(4.4+0.1) \mathrm{eV}$. Down to $70 \mathrm{eV}$ this distribution does not show any appreciable alteration, except a decrease in intensity. The $\mathrm{O}^{2+}$ ion current being five times lower than that of $\mathrm{N}^{2+}$ at $100 \mathrm{eV}$ electron energy, such an intensity made impossible the recording of the first differentiated retarding curve near threshold in a reasonable time.

The direct as well as the first differentiated ionization efficiency curves of $\mathrm{O}^{2+}$ from $\mathrm{O}_{2}$ have been analyzed as shown in fig. 5 . The lowest onset measured by the methods described above, is $(60.5 \pm 0.8) \mathrm{eV}$. This energy agrees fairly well with the onset calculated for the process

$$
\mathrm{O}^{2}+\mathrm{e}^{-} \rightarrow O\left({ }^{1} \mathrm{~S}\right)+\mathrm{O}^{2+}\left({ }^{1} \mathrm{D}\right)+3 \mathrm{e}^{-}
$$


at $60.552 \mathrm{eV}$ using $\mathrm{D}_{0}{ }^{0}\left(\mathrm{O}_{2}\right)=5.115 \mathrm{eV}$ [9], IP(OI, $\left.{ }^{3} \mathrm{P}_{2}\right)=13.618 \mathrm{eV}[10], \mathrm{IP}\left(\mathrm{OI},{ }^{4} \mathrm{~S}^{\circ}\right)=35.116 \mathrm{eV}[10]$ and $\mathrm{O}\left({ }^{1} \mathrm{~S}\right.$ $\left.\leftarrow^{3} \mathrm{P}\right)=4.190 \mathrm{eV}[11]$ and $\mathrm{O}^{2+}\left({ }^{1} \mathrm{D} \leftarrow{ }^{4} \mathrm{~S}^{\circ}\right)=2.513 \mathrm{eV}$ [11]. This onset is related to the formation of thermal energy $\mathrm{O}^{2+}$ ions.

Fig. 3. Onset energy values for the four groups of ions observed in the ion energy distribution recorded for 100 eV electron energy.

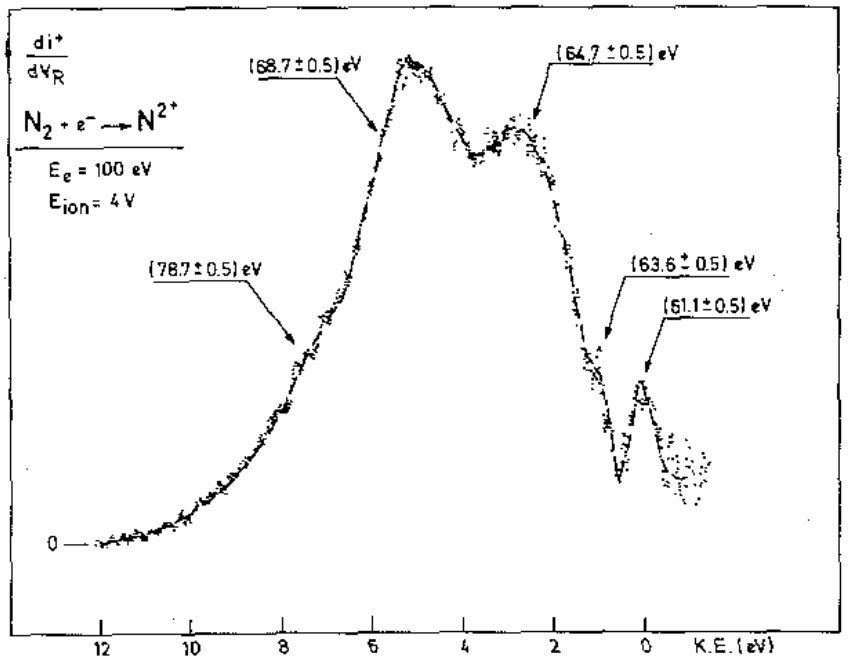

Fig. 4. $\mathrm{O}^{2+} / \mathrm{O}_{2}$ ion energy distribution observed for $100 \mathrm{eV}$ electron energy. The threshold energy measured for each ion group is given above the corresponding arrow.

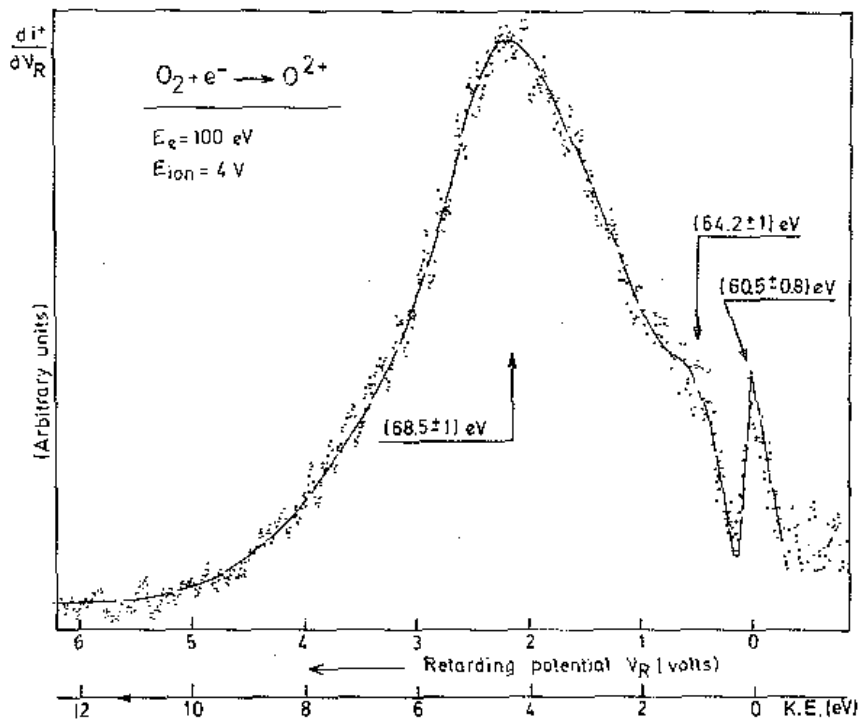

However, the accuracy of the measurements does not allow us to exclude the possibility of transitions to one of the two dissociation limits

$$
\begin{aligned}
& \mathrm{O}_{2}+\mathrm{e}^{-} \rightarrow \mathrm{O}\left({ }^{1} \mathrm{D}\right)+\mathrm{O}^{2+}\left({ }^{1} \mathrm{~S}\right)+3 \mathrm{e}^{-}, \\
& \mathrm{O}_{2}+\mathrm{e}^{-} \rightarrow \mathrm{O}\left({ }^{3} \mathrm{P}_{2}\right)+\mathrm{O}^{2+}\left({ }^{5} \mathrm{~S}\right)+3 \mathrm{e}^{-},
\end{aligned}
$$


for which the threshold is calculated at $61.170 \mathrm{eV}$ and at $61.326 \mathrm{eV}$ respectively $\left(\mathrm{O}\left({ }^{1} \mathrm{D} \leftarrow{ }^{3} \mathrm{P}_{2}\right)=1.967 \mathrm{eV}, \mathrm{O}^{2+}\left(\mathrm{S}_{\leftarrow} \leftarrow 3 \mathrm{P}_{0}\right)=\right.$ $5.354 \mathrm{eV}$ and $\left.\mathrm{O}^{2+}\left({ }^{5} \mathrm{~S} \leftarrow{ }^{3} \mathrm{P}_{0}\right)=7.477 \mathrm{eV}[11]\right)$.

Fig. 5. First differentiated (a) and direct (b) ionization efficiency curve of $\mathrm{O}^{2+} / \mathrm{O} 2$ as recorded at $V_{R}=0 \mathrm{~V}$ and an ion accelerating voltage of $E_{\text {ion }}=5 \mathrm{~V}$.

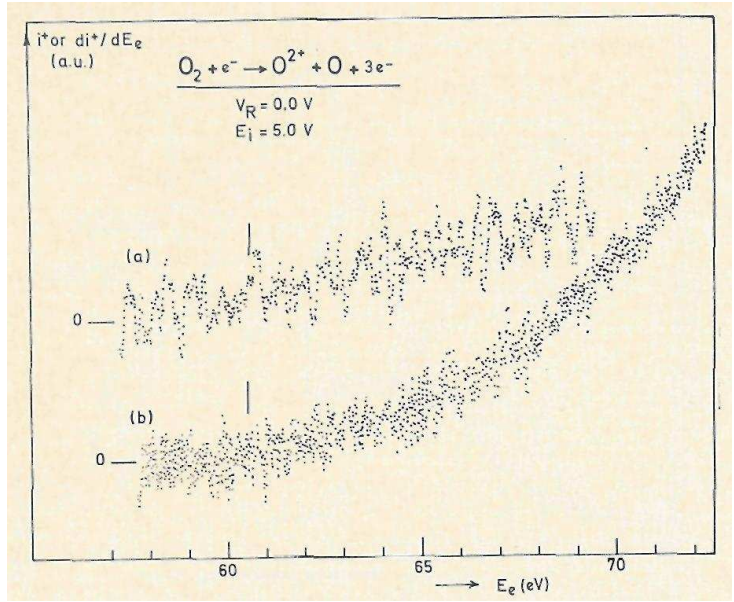

As for $\mathrm{N}^{2+}$ from $\mathrm{N}_{2}$, the appearance energy has been measured for the two other groups of ions observed in the ion energy distribution (see fig. 4). For the $1.4 \mathrm{eV}$ group, the onset is observed at $(64.2 \pm 1) \mathrm{eV}$ and a threshold energy of $(68.5+1) \mathrm{eV}$ has been measured for $4 \mathrm{eV} \mathrm{O}^{2+}$ ions. Within the accuracy of the onset energies, the energy balance indicates that for both ion groups the same dissociation limit is involved.

\section{Acknowledgement}

We are indebted to the Fonds National de la Recherche Scientifique and to the Fonds de la Recherche Fondamentale Collective for financial support.

\section{REFERENCES}

[1] H.D. Hagstrum and J.T. Tate, Phys. Rev. 59 (1941) 354.

[2] LJ. Kieffer and R.J. van Brunt, J. Chem. Phys. 46 (1967) 2728.

[3] A. Crowe and J.W. McConkey, J. Phys. B 8 (1975) 1765.

[4] L. Deleanu and J.A.D. Stockdale, J. Chem. Phys. 63 (1975) 3898.

[5] A.K. Edwards, R.M. Wood and M.F. Steucr, Phys. Rev. 15 (1977)48.

[6] A.C. Hurley, J. Mol. Spectry. 9 (1962) 18.

[7] R. Locht and J. Schopman, Intern. J. Mass Spectrom. Ion Phys. 15 (1974) 361.

[8] R. Locht, J. Schopman, H. Wankenne and J. Momigny, Chem. Phys. 7 (1975) 393.

[9] B. de B. Darwent, Bond Dissociation Energies in Simple Molecules, NSRDS-NBS 31 (1975).

[10] C.E. Moore, Ionization Potentials, and Ionization Limits Derived from the Analysis of Optical Spectra, NSRDS-NBS 34 (1970).

[11] C.E. Moore, Atomic Energy Levels, NBS Circular 467 (1949).

[12] G.H. Dunn, Phys. Rev. Letters 8 (1962) 62. 